\title{
LA ESTRUCTURA DEL DISCURSO EN EL QUIJOTE
}

Algunos breves análisis que he venido haciendo durante los últimos lustros me han permitido advertir que la prosa castellana llegó a su más amplia y compleja organización sintáctica durante las últimas décadas del siglo XV y las primeras del XVI, esto es a fines de la Edad Media y a comienzos del Siglo de Oro español. Los textos de esta época que, para llegar a tal conclusión, analicé fueron la Cárcel de amor y el Prólogo de Nebrija a su Gramática de la lengua castellana y las Cartas de relación de Hernán Cortés, obras que confronté con escritos de otras épocas ${ }^{1}$. Me propongo mostrar aquí cómo es la estructura sintáctica de la prosa cervantina a través del análisis gramatical de cinco pasajes del Quijote de carácter narrativo $^{2}$, de igual extensión ${ }^{3}$, y tomados al azar. Naturalmente que es-

1 Desde el Calila e Digna hasta las obras de cinco escritores mexicanos de nuestro tiempo -A. Reyes, M. L. Guzmán, A. Yáñez, O. Paz y J. Rulfo-, pasando por los Comentarios reales del Inca Garcilaso, por diversos escritos de Quevedo y por el Oráculo manual de Gracián.

2 De naturaleza semejante a la de los escritos estudiados anteriormente, en los cuales evité también incluir pasajes dialogados, por cuanto que la estructura sintáctica del diálogo es un tanto diferente de la peculiar de la narración.

3 Todos ellos de alrededor de 500 unidades léxicas: la Muestra 1, perteneciente al «Prólogo» de la Primera parte del Quijote, consta de $\mathbf{5 1 0}$ palabras aproximadamente, así como la M-3, entresacada del famoso discurso de las armas y las letras (cap. 38), en tanto que la M-2 (del cap. 27) reúne un total de 490 unidades léxicas, cantidad igual a la de M-4, tomada del cap. 17 de la Segunda parte; la última muestra, la M-5, consta de 500 palabras y pertenece al capitulo 69 . Me he basado en la edición crítica hecha por Francisco Rodríguez Marín para la editorial Atlas de Madrid en diez volúmenes, aunque para fijar con mayor seguridad la puntuación de los textos - cuestión de suma importancia cuando de hacer análisis oracionales se trata- he tenido en cuenta la edicion princeps en su impresión facsímile hecha 
tos cinco breves pasajes resultan por completo insuficientes para determinar con precisión cómo organizaba Cervantes, desde el punto de vista sintáctico, su discurso escrito, pero sí permiten descubrir las líneas esenciales de su expresión, y confrontarlas con las propias de los otros escritores cuya prosa ya he analizado también esquemáticamente.

Para hacer el análisis gramatical de los pasajes cervantinos, me serviré del mismo procedimiento que he empleado al analizar los textos de los otros escritores ya mencionados, método que queda explicado en un libro en que reuní estudios sobre la estructura de la cláusula en la lengua escrita y en la hablada ${ }^{4}$; en consecuencia, presentaré aquí tal método de manera muy sucinta pero suficiente - espero- para la adecuada comprensión de las observaciones que haré en estas páginas. Los instrumentos con que hago los análisis son, básicamente, los siguientes: De un lado, la cláusula; del otro, la oración y sus equivalentes funcionales, o sea la frase, la prooración y el período.

Considero que -de acuerdo con la tradición gramatical española ${ }^{5}$ - el nombre de oración, en cuanto a unidad morfosintáctica, o sea gramatical, corresponde al enunciado bimembre entre cuyos dos elementos constitutivos se establece una relación predicativa. Este concepto de la oración, de raíz aristotélica, ha sido esquematizado por Karl Bühler mediante la fórmula $[\mathrm{S} \rightarrow \mathrm{P}]^{6}$. Así, son oraciones gramaticales enunciados de las siguientes clases: "Las aves vuelan", "Colón descubrió América», "Las cuentas, claras", "Los niños, delante», "¡Qué bella actitud la tuya!» o "¿Quién lo hizo?", expresiones en todas las cuales aparecen al menos dos miembros en relación predicativa.

La cláusula, en cambio, queda definida por su autonomía elocutiva y su plenitud semántica, ya que es unidad de manifestación o comunicación, no unidad formal, gramatical, morfosintáctica: Carece de estructura sintáctica propia, ya que puede estar constituida por una sola palabra, por una sola frase, por una oración o prooración, o por uno o varios períodos. Son, pues, cláusulas enunciados tan distintos formalmente como «¡Caramba!», «¡El diluvio!»,

en Barcelona por Montaner y Simón en 1897. En la edición de Rodríguez Marín los textos elegidos ocupan las siguientes páginas: $\mathbf{M}-1=$ vol. $\mathrm{I}, \mathrm{p} .17$ a $22, \mathrm{lín}$. 6 ; M-2 = vol. II, p. 308 a $309 ; M-3=$ vol. III, de p. 157 , lín. 9 a p. $160 ; M-I V=$ vol. V, p. 54 a 55 , lín. 18, y $\mathbf{M}-\mathrm{V}=$ vol. VIII, p. 177 a 179.

4 Cf. mi Análisis gramatical del discurso. México, Universidad Nacional Autónoma de México, 1983 (2." ed., 1984).

5 Cf. mi librito sobre El concepto de oración en la lingütstica española. México, UNAM, 1979 (2.* ed., 1989).

- Cf. su Teoría del lenguaje (Traducción española de Julián Marías). Madrid, 1950 , pp. 413 ss. 
«Buenos días», «En la oficina», "Todas las noches», "Dramática devaluación del dólar en todos los mercados financieros", "Las aves vuelan", o "Cuando lo acabes, haz el favor de avisarme para que lo revise y te diga si ha quedado bien o tienes que perfeccionarlon.

El nombre de frase lo reservo para la expresión constituida por una sola palabra o, más frecuentemente, por varias palabras ordenadas en torno a un elemento nuclear - por lo común, un nombre-, pero que no está estructurada dicotómicamente en [S $\rightarrow \mathrm{P}$ ]. Por ejemplo: «¡Diablos!», “¡Caramba con el niño!», «Una limosna, por caridad", "Insistentes demandas de los trabajadores por aumento de sueldo" ?

Denomino prooración al enunciado unimembre o plurimembre de estructura no oracional que implica o reproduce una oración o frase ya enunciada. Por ejemplo "Yo" como respuesta a la pregunta "¿Quién lo hizo?" o "En casa de Luis" en cuanto comentario o adición a una oración anterior como "Nos reuníamos todas las tardes" ${ }^{8}$.

Reservo el nombre de periodo, finalmente, para designar al enunciado constituido por dos o, algunas veces, varias oraciones o frases entre las que se establece una sola relación sintáctica, ya coordinante, ya subordinante. Ejemplos: «Estudia mucho, pero aprende poco" (período adversativo restrictivo); "Si viene, atiéndele bien" (período condicional); "Llegué, vi y vencín (período copulativo); "Amplias ganancias en la Bolsa, pero acusada devaluación de la moneda» (período adversativo entre frases).

Con estos sencillos instrumentos de análisis sintáctico he estudiado los cinco pasajes del Quijote señalados, y he llegado a las siguientes conclusiones, según se desprenden de los cuadros que presento a continuación.

CUADRO 1

ESTRUCTURA DEL DISCURSO

\begin{tabular}{|c|c|c|c|c|c|c|c|}
\hline & M-1 & M-2 & M-3 & M-4 & M-5 & Total & Promedic \\
\hline láusulas & 11 & 11 & 13 & 14 & 12 & 61 & 12,2 \\
\hline 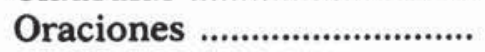 & 75 & 96 & 82 & 73 & 63 & 389 & 77,8 \\
\hline 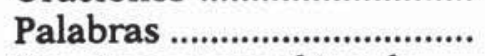 & 510 & 490 & 510 & 490 & 500 & 2.500 & 500 \\
\hline ciones por cláusula .... & 6,8 & 8,7 & 6,3 & 5,2 & 5,3 & & 6,4 \\
\hline Palabras por oración ......... & 6,8 & 5,1 & 6,2 & 6,7 & 7,9 & & 6,4 \\
\hline alabras por cláusula ........ & 46,4 & 44,5 & 39,2 & 35 & 41,7 & & 41 \\
\hline
\end{tabular}

7 La forma oracional correspondiente a ese periodo seria «Los trabajadores demandan insistentemente un aumento de sueldox.

- En el primer caso «yo» implica la oración anterior, puesto que significa «Yo lo hice»; y «En casa de Luis», por su parte, retoma también la oración a que complementa o completa: «Nos reuníamos todas las tardes en casa de Luis». 
CUADRO 2

ESTRUCTURA DEL PERÍODO

Orac. princip.

$\frac{M-1}{11} \frac{M-2}{11} \frac{M-3}{13} \frac{M-4}{14} \frac{\text { M-5 }}{\begin{array}{r}12 \\ 3\end{array}} \frac{\text { Total }}{\begin{array}{r}61 \\ 3\end{array}} \frac{\left.\begin{array}{r}r, 7 \\ 0,8\end{array}\right] 16,5}{15}$

Períod. copul.

$\left.\begin{array}{rrrrrrr}3 & 2 & 1 & 11 & 6 & 23 & 5,9 \\ 1 & 3 & & 1 & 1 & 6 & 1,5 \\ 3 & 1 & & & 1 & 2 & 0,5 \\ 1 & & 2 & & & 5 & 1,3 \\ 1 & & & 1 & 2 & 4 & 1\end{array}\right)^{10,3}$

Per, adver. res.

Per. adver. exclus.

$\begin{array}{llll}3 & 6 & 7 & 15\end{array}$

Per. sujetivos

$\begin{array}{rrr}3 & 6 & 7 \\ 13 & 22 & 2 \\ & & 11\end{array}$

Per. objetivos

Per. prepositivos

$\begin{array}{rr}13 & 22 \\ & 2\end{array}$

$15 \quad 3 \quad 34$

8,7

6

$4 \quad 2$

0,5
24,2

Per. adnominal

2

Per. adj. expli.

Per. adj. especif.

$\begin{array}{rrr}5 & 2 & 1 \\ 7 & 9 & 12\end{array}$

3

4

2

0,5

Per. modales

Per. temporales

Per. locativos

1

29

$2,3 \quad 2,3$

Per. comparativos ............ 2

Per. consecutivos

$7 \quad 10$

$\begin{array}{lll}4 & 10 & 22\end{array}$

$$
\left.\begin{array}{l}
5,6 \\
9,2
\end{array}\right] 14,9
$$

$\begin{array}{rrr}7 & 10 & 4 \\ 1 & 4 & 4 \\ & 1 & 1\end{array}$

$\left.\begin{array}{rrrr}2 & 7 & 30 & 7,7 \\ 1 & 3 & 13 & 3,3 \\ & & 2 & 0,5\end{array}\right] 11,5$

Per. consecutivos....

2

Per. causales

$\begin{array}{lll}8 & 8 & 15\end{array}$

Per. finales

Per. condicion.

Per. concesivos

$\begin{array}{rrr}4 & 7 & 1 \\ & 3 & 1 \\ 2 & 4 & 1\end{array}$

5

$\left.\begin{array}{lll} & 9 & 2,3 \\ 1 & 4 & 1\end{array}\right] 3,3$

$\left.\begin{array}{rrr}5 & 40 & 10,3 \\ 13 & 3,3 \\ 5 & 1,3 \\ 8 & 2\end{array}\right) 17$

Total de subordinación adverbial $=31,9 \%$

Oraciones regentes: $\quad 64=16,5$

Oraciones coordinadas: $\quad 40=10,3$

Oraciones subordinadas: $285=73,3$

Adviértase en ellos, inmediatamente, un rasgo notable de la prosa cervantina: en gran variedad sintáctica. Variedad que se aprecia en diversos niveles o sectores, comenzando - dentro de la estructura del discurso- por la diversidad formal de las cláusulas, para acabar - dentro de la estructura del período- por la riqueza de las relaciones existentes entre unas oraciones y otras. Aproximémonos un poco a todo ello:

La integración oracional de la cláusula y la amplitud léxica de cada una de las oraciones y de cada una de las cláusulas varía de 
una muestra a otra notoriamente ${ }^{9}$. En efecto, salvo dos casos evidentes de coincidencia -entre las muestras 4 y 5 en lo que se refiere al número de oraciones integrantes, en promedio, de cláusula (5,2 y 5,3 respectivamente), y entre las muestras 1 y 4 en lo que respecta al número de palabras integrantes, también en promedio, de oración $(6,8$ y 6,7$)$ - en todos los demás casos prevalece una relativa divergencia. Diversidad que alcanza sus extremos entre las muestras 2 y 5 . En efecto, el número de oraciones gramaticales que figuran en esas dos muestras es muy diferente en cada caso: 63 oraciones en el pasaje 5 frente a 96 en el 2, lo cual quiere decir que éste supera en un 52 por 100 al primero. Y, como consecuencia inmediata de ello, la estructura oracional de las cláusulas varía notablemente: a las 5,3 oraciones integrantes de cada cláusula, en promedio, de la muestra 5 corresponden 8.7 oraciones de la muestra 2, lo cual equivale a un 64 por 100 de mayor complejidad oracional. De ahí, también, que la amplitud léxica de la oración peculiar de la muestra 2 (de 5.1 palabras por oración), aumente acusadamente en la muestra 5 : casi 8 palabras por oración, es decir, un 55 por 100 más. También es notable la diferencia existente, en lo que a la integración léxica de la cláusula respecta, entre la muestra 4 (sólo 35 palabras por cláusula) y la muestra 1 (46,4 unidades léxicas, o sea un $32,6 \%$ más).

Paralela variedad sintáctica existe en la constitución oracional de unas y otras cláusulas. Construye a veces Cervantes cláusulas de gran aliento, de amplia envergadura, integradas por hasta 19 ó 20 oraciones, en tanto que otras veces se expresa por medio de cláusulas breves, concisas, constituidas por sólo una o dos oraciones gramaticales. Véase, por ejemplo, la complejidad sintáctica de la siguiente cláusula, perteneciente a la muestra 2 , en la cual figuran oraciones de muy diversa clase: condiciones, modales, objetivas, adjetivas explicativas y especificativas, causales y finales:

Y que si le preguntase, como se lo había de preguntar, si dio la carta a Dulcinea, dijese que sí, y que por no saber leer le había respondido de palabra, diciéndole que le amaba, so pena de la su desgracia, que luego al momento se viniese a ver con ella, que era cosa que le importaba mucho, porque con esto y con lo que ellos pensaban decirle tenían

9 Quizá esté de más señalar que los términos de comparación deben establecerse entre promedios globales. La constitución oracional, por ejemplo, puede variar mucho de una cláusula a otra dentro de una misma muestra o pasaje; de ahí la conveniencia de atender a los promedios extraídos - y representantes- de cada muestra. También me parece obvio que los datos que aquí reúno no pueden considerarse, de ninguna maneram definitivos, sino que deben tomarse como simples síntomas o apreciaciones provisionales sobre el estilo -0 la construcción sintáctica- de Cervantes. Cinco breves muestras aisladas del Quijote son, repito,testimonio insuficiente para pretender llegar a conclusiones firmes. 
por cosa cierta reducirle a mejor vida y hacer con él que luego se pusiese en camino para ir a ser emperador o monarca, que en lo de ser arzobispo no había de qué temer ${ }^{10}$.

Pero, otras veces, una o dos oraciones bastan para integrar la cláusula: "Todos los caballeros tienen sus particulares ejercicios» (Muestra 4). «Pero no he podido yo contravenir a la orden de naturaleza, que en ella cada cosa engendra su semejante» (Muestra 1: vol. I, p. 17).

Cierto es que una cláusula constituida por una sola oración gramatical puede alcanzar generosa amplitud léxica mediante la sucesión de complementos oracionales, como sucede, por ejemplo, en el siguiente pasaje de la muestra 5: "Tenía la cabeza sobre una almohada de brocado, coronada con una guirnalda de diversas y odoríferas flores tejida, las manos cruzadas sobre el pecho y entre ellas un ramo de amarilla y vencedora palma» (vol. VIII, p. 177).

Esa variedad expresiva en el estilo de Cervantes se advierte asimismo en la organización de los períodos. En las cinco breves muestras analizadas he hallado un elevadísimo número y una gran variedad de períodos gramaticales. De las 25 clases de relaciones interoracionales con que cuenta la lengua española, ha empleado Cervantes, en tan reducidos textos, un total de 22; sólo echo de menos tres clases de períodos, de muy baja vitalidad, por cierto, dentro de la sintaxis española: el distributivo, el de complemento indirecto y el agentivo ${ }^{11}$. El primero de ellos alcanza apenas el 0,3 por 100 de empleo en la expresión castellana; el complementario indirecto sólo llega al 0,2 por 100; y el agentivo es tan inusitado, que la gramática española lo había pasado por alto durante siglos, según señalo en el artículo citado en la nota anterior ${ }^{12}$. Todos los demás períodos existentes en la expresión hispánica aparecen, en mayor o menor proporción ${ }^{13}$, en los breves textos analizados, los cuales se convierten así en un riquísimo muestrario de la sintaxis oracional española ${ }^{14}$.

10 Vol. II, p. 309 en la edición crítica de Rodríguez Marín citada en la nota 3 , por la cual hago todas las referencias.

11 Véase, en lo que respecta al agentivo, mi nota sobre «Una clase olvidada de oraciones sustantivas», en Revista de Filologia Española, 73, 1993, 65-68.

12 Los índices de empleo señalados aquí los tomo de un estudio sobre la $\propto \mathrm{Vi}$ talidad de los diversos períodos gramaticales en español» incluido en mi libro de Nuevos estudios de lingütstica hispánica. México, UNAM, 1993, pp. 45-57.

13 Que va del 14.4 por 100 en el caso de los perfodos objetivos al 0,5 por 100 en el de los adversativos restrictivos, los predicativos, los prepositivos y los locativos.

14 Aparece en estos textos, inclusive, una prooración, forma expresiva propia de la lengua hablada, del diálogo, pero rarísima en textos narrativos. (Cf. mis «Notas sobre las unidades sintácticas del discurso», Anuario de Letras, XX, 1982, pp. 333-344). Tal cosa sucede en la última cláusula de la muestra 2: «y si le preguntase... dijese que st» (vol. II, p. 309). 
Otro rasgo sobresaliente de la prosa cervantina es la elevada frecuencia de construcciones hipotácticas, en desmedro de la parataxis. El promedio general de uso de ambas sintaxis es bien significativo: 73,3 por 100 en el caso de la subordinación y sólo 10,3 por 100 en el de la coordinación. Esto revela también cuán elaborado y complejo es el modo de expresión peculiar de Cervantes: prosa trabajada, rica, amplia, que evidencia un perfecto dominio de la sintaxis, de la lengua misma.

Pues bien, esa distribución proporcional tan favorable a la subordinación, se quebranta a veces, para dar paso a cláusulas en que la coordinación se sobrepone totalmente a la hipotaxis, quebranto éste que es un recurso estilístico más de Cervantes y que hace patente, de nuevo, la variedad de su expresión. Ejemplo notable de ello pueden ser dos cláusulas consecutivas de la muestra 4 adversativas restrictivas entre sí- en que la oración regente inicial de la primera de ellas va seguida de cinco oraciones copulativas, a las que remata una ilativa, en tanto que la oración regente de la segunda cláusula se completa con seis períodos copulativos, los cuales van seguidos de uno causal y de tres sujetivos, también copulados entre sí:

Sirva a las damas el cortesano, autorice la corte de su rey con libreas, sustente los caballeros pobres con el espléndido plato de su mesa, concierte justas, mantenga torneos y muéstrese grande, liberal y magnífico y buen cristiano sobre todo, y desta manera cumplirá con sus precisas obligaciones; pero el andante caballero busque los rincones del mundo, éntrese en los más intrincados laberintos, acometa a cada paso lo imposible, resista en los páramos despoblados los ardientes rayos del sol en la mitad del verano y en el invierno la dura inclemencia de los vientos y de los yelos, no le asombren leones ni le espanten vestiglos, ni atemoricen endriagos, que buscar éstos, acometer aquéllos y vencerlos a todos son sus principales y verdaderos ejercicios (vol. V, pp. 54-55).

La fisonomía sintáctica de este pasaje contrasta violentamente con la del ejemplo citado líneas antes, en que la oración principal iba acompañada de 18 oraciones - y de una prooración-, todas ellas subordinadas de diversa naturaleza, en tanto que la coordinación sólo se da internamente -o secundariamente- en dos ocasiones, entre oraciones sintácticamente subordinadas objetivas pero copuladas entre sí: «...que ellos tenían por cosa cierta reducirle a mejor vida $y$ hacer con él que...» (II, p. 309).

Una prueba más de la rica variedad del estilo cervantino podría ser la diversidad en el orden de las oraciones regentes dentro de cada cláusula. Aunque lo común y general es que sea la oración principal la que inicie la cláusula, siguiendo así un orden lineal descendente («Otro día llegaron al lugar donde Sancho había deja- 
do puestas las señales de las ramas para acertar el lugar donde había dejado a su señor»: II, 309), no faltan ejemplos de anteposición de oraciones subordinadas, dando paso, así, a una ordenación circular o envolvente: «Y entre las que he dicho, dicen las letras que sin ellas no se podrían sustentar las armas, porque...» (III, 158). La anteposición de la oración subordinada suele producirse cuando ésta es temporal: "Mas apenas hubo salido de la venta, cuando le vino al Cura un pensamiento..." (II, 308); "Al subir el Duque y la Duquesa en el teatro, se levantaron don Quijote y Sancho, y les hicieron una profunda humillación" (VIII, 179). Pero no faltan ejemplos de anteposición de oración subordinada de diversa naturaleza, como una concesiva («aunque es mayor el trabajo del soldado, es mucho menor el premio»: III, 158), o una modal («sin que se lo señalaran, callaran ellos»: VIII, 178). En algunas ocasiones, la oración regente va precedida por dos 0 , inclusive, por tres oraciones subordinadas de diferente clase: "Y estando una [vez] suspenso, con el papel delante, la pluma en la oreja... pensando lo que diría, entró a deshora un amigo mío...» (I, 21-22); "así como es más fácil venir el pródigo a ser liberal que el avaro, asi es más fácil dar el temerario en verdadero valiente que no el cobarde subir a la verdadera valentía» $(V, 55)$. Parecería, en conclusión, que Cervantes se esfuerza por evitar incurrir en fatigosa monotonía expresiva, y procura, en cambio, deleitar a los lectores a través de su acusada variedad sintáctica, como base formal del deleite conceptual de su relato.

Otro rasgo acusado del discurso cervantino es la trabazón formal que suele dar a sus escritos. Para ello, recurre al empleo de conjunciones o locuciones nexuales interclausulares, que alternan ventajosamente con la simple yuxtaposición de las cláusulas. De las 61 que integran el corpus analizado, 31 de ellas van encadenadas a la anterior por algún nexo: «quisiera que este libro... fuera el más hermoso, que pudiera imaginarse. Pero no he podido yo contravenir a la orden de naturaleza» (I, 17). La conjunción que con más frecuencia aparece empleada como nexo interclausular es la copulativa $y$ (10 veces): «...tiene licencia de usar de sus privilegios y de sus fuerzas. $Y$ es razón averiguada que aquello que más cuesta se estima en más» (III, 158); «...que vuesa merced no me tenga... por un hombre disparatado y loco? $Y$ no sería mucho que así fuese" $(V, 54)$. También la adversativa pero aparece con mucha frecuencia (8 veces): «aunque es mayor el trabajo del soldado, es mucho menor el premio. Pero a esto se puede responder que...» (III, 158). Con sólo dos -o aun una- apariciones figuran otros muy diversos nexos, como $y$ asi, asi que o pues, empleados con valor ilativo: «....acometer todo aquello que a mí me pareciere que cae debajo de la juridición de mis ejercicios; $y$ asi el acometer los leones que ahora 
acometí derechamente me tocaban $(\mathrm{V}, 55)$; «porque de faldas... todos tienen en qué entretenerse; así que, aunque es mayor el trabajo del soldado, es mucho menor el premio» (III, 158); «...buscar éstos, acometer aquéllos y vencerlos a todos son sus principales y verdaderos ejercicios. Yo, pues, como me cupo en suerte ser uno del número de la andante caballería, no puedo dejar de acometer...» $(\mathrm{V}, 55)$. Asimismo, en dos ocasiones, mas, con función adversativa, alternando con pero: «...que Dios les diese buen suceso en tan arduo... negocio como era el que habían emprendido. Mas apenas hubo salido de la venta, cuando le vino al Cura un pensamiento" (II, 308). También emplea Cervantes como nexos interclausulares porque y que, ambos con sentido causal: «...sin el ornato de ... elogios que al principio de los libros suelen ponerse. Porque te sé decir que..." (I, 21); "...menos mal será que el que es valiente suba al punto de temerario que no que baje... al de cobarde; que... es más fácil dar el temerario en verdadero valiente que...» $(\mathrm{V}, 55)$. La función nexual puede estar desempeñada por algún pronombre relativo: «...dobló sus vestidos, y el Cura acomodó su barba, y siguieron su camino, guiándolos Sancho Panza; el cual les fue contado lo que...» (II, 305); "...se dice que "debajo de mi manto, al Rey mato". Todo lo cual te esenta y hace libre...» (I, 19-20). Completa la nómina la locución explicativa en efecto, documentada una vez: «...y de ver a los dos en aquel traje no pudo tener la risa. En efeto, el Barbero vino en todo aquello que el Cura quiso y..." (II, 308).

No me detendré aquí a considerar los recursos estilísticos empleados por Cervantes - paralelismo, pregunta retórica, reiteración, encadenamiento, etc.-, ya que sólo pretendo destacar las peculiaridades gramaticales, sintácticas, de su estilo.

Las cuales quedan más claramente delineadas cuando se comparan con las características de otros escritores ${ }^{15}$, cosa que permiten hacer con facilidad los cuadros 3 y 4 .

Como puede verse, la sintaxis cervantina se sitúa en un punto intermedio entre la complejidad sintáctica máxima alcanzada por la prosa de Nebrija y de Hernán Cortés, y la sencillez estructural

15 Tomo en consideración obras literarias cuya estructura sintáctica ya he analizado, siquiera sea esquemáticamente, en otros lugares, la mayor parte de los cuales han quedado recogidos en el libro citado en la nota 4, donde se incluyen los estudios en torno a la Cárcel de amor, el inca Garcilaso de la Vega, Quevedo y Gracián. A ellos habría que añadir el estudio de las estructuras sintácticas usadas por Nebrija y por Hernán Cortés; lo primero, en mi libro Nebrija cinco siglos después (México, UNAM, 1994, pp. 99-112), y lo segundo, en la ponencia presentada en el IV Congreso Internacional sobre El español de América (Santiago de Chile, dic. de 1992; aún inédito), donde analicé la estructura de la cláusula en las Cartas de relación del conquistador de México. 
CUADRO 3

\section{ESTRUCTURA DE LA CLÁUSULA}

\begin{tabular}{|c|c|c|c|c|c|c|c|c|}
\hline & Cerv. & Cárcel & Nebr. & Cort. & Garci. & Quev. & Grac. & Escr. Mex. \\
\hline & 6,4 & 4,8 & 8,4 & 9,4 & 4,8 & 4,9 & 2,9 & 4,3 \\
\hline & 6,4 & 5,6 & 7,7 & 7,4 & 5,6 & 5,2 & 4,6 & 7 \\
\hline láus. ...... & 41 & 27 & 65 & 69 & 27 & 25 & 13,5 & 22 \\
\hline
\end{tabular}

de la expresión graciana. En efecto, la organización oracional de la cláusula en el Quijote (6,4 oraciones por cada cláusula, siempre en promedio) está muy lejos de la enorme complejidad o amplitud a que llegó la prosa de Hernán Cortés ${ }^{16}(9,4$ oraciones por cláusula) o la de nebrija $(8,4)$, a la vez que queda también alejada de la acusada sencillez estructural del estilo de Gracián ( 2.9 oraciones por cláusula) y aun de los escritores mexicanos de nuestro siglo $(4,3)$. A este repecto, la sintaxis cervantina ocupa, pues, un lugar intermedio, de equilibrio, entre los dos extremos, con ligera inclinación hacia la construcción amplia, conscientemente elaborada. Equilibrio o situación intermedia que también se advierte con claridad en lo que respecta a la constitución léxica de la oración gramatical: 6,4 palabras en promedio, frente a las 7,7 de Nebrija y a las 4,6 de Gracián o 5,2 de Quevedo. Y lo mismo sucede en el caso de la integración léxica de las cláusulas: su dimensión en el Quijote (41 palabras por cláusula) no tiene ni la extensión extrema de las Cartas cortesianas (69 unidades léxicas) ni la reducida brevedad de la prosa graciana $(13,5)$ o aun de los escritores de nuestro tiempo (22), sino que está cerca de lo que sería el promedio general resultante de la suma de las estructuras léxicas de esos diversos autores ${ }^{17}$.

La consideración de los datos estadísticos recogidos en el cuadro 4 permite advertir otras peculiaridades del estilo cervantino.

Muchas y muy diversas consideraciones podrían hacerse a partir de estos datos. En primer lugar, se advierte que en todos los casos - con una sola excepción a que me referiré en seguida- las cifras correspondientes a las estructuras sintácticas del Quijote ocupan un lugar interior, intermedio, entre los extremos marcados por

16 Que, para mi sorpresa, ha sido la más compleja y extendida de cuantas he tenido oportunidad hasta ahora de analizar, sólo comparable con la también generosa, compleja y dilatada de Nebrija. Y se da la circunstancia de que los dos escritos de ellos estudiados coinciden en ser textos dirigidos a sus respectivos monarcas: el de Nebrija -el Prólogo de su Gramática - a la reina Isabel; el de Cortés, al emperador Carlos V. No me parece coincidencia fortuita, sino determinante, que se suma a la coincidencia de época. (Cf., a este respecto, lo que anoto en el libro sobre Nebrija citado en la nota anterior, pp. 110-111).

17 El promedio de todos ellos sería 36 palabras por cláusula, al que se aproxima el cervantino (41) más que ninguno otro. 
CUADRO 4

ESTRUCTURA DE LOS PERIODOS

Orac. regent.

\begin{tabular}{|c|c|c|c|c|c|c|}
\hline $\begin{array}{c}\text { Cerv. } \\
\%\end{array}$ & $\begin{array}{c}\text { Cárcel } \\
\%\end{array}$ & $\begin{array}{c}\text { Nebrija } \\
\%\end{array}$ & $\begin{array}{c}\text { Cortés } \\
\%\end{array}$ & $\begin{array}{c}\text { Garc. } \\
\%\end{array}$ & $\begin{array}{l}\text { Quev. } \\
\%\end{array}$ & $\begin{array}{c}\text { Escr. Mex. } \\
\%\end{array}$ \\
\hline 16,5 & 20,8 & 11,9 & 10,7 & 22 & 20,5 & 31,4 \\
\hline
\end{tabular}

Orac. coord.

Total parat.

$\frac{10,3}{26,8} \frac{11,2}{32} \frac{7,2}{19,1} \frac{15,3}{26} \frac{10,2}{32,2} \frac{14,2}{34,7} \frac{19}{50,4}$

Subor. sust.

$26,5 \quad 18$

Subor. adjet.

$14,4 \quad 9$

$16,1 \quad 19,6$

$18,1 \quad 24,1$

16,4

Subor. adver.

$\frac{31,9}{73,3} \frac{41}{68}$

Total hipot.

$73,3 \quad 68$

28,8

23,6

$21,5 \quad 11,9$

18,5

Total hipot.

73,3

otros estilos. Así la proporción de oraciones regentes en la prosa de Cervantes $(16,5 \%)$ está a medio camino entre la máxima del inca Garcilaso $(22 \%)$ y la mínima de Hernán Cortés $(10,7 \%)^{18}$. De igual manera, el promedio de períodos coordinados propio de Cervantes $(10,3 \%)$ se sitúa entre el extremo superior propio de Cortés $(15,3 \%)$ y el inferior, de Nebrija (7,2\%). Y así en casi todos los demás casos, lo cual invita a concluir que la sintaxis oracional de Cervantes posee también una contextura equilibrada, armoniosa, dentro de la serie de estilos sintácticos hasta aquí considerados. Sólo en una ocasión la sintaxis cervantina ocupa uno de los extemos de la cadena: en el caso de las oraciones subordinadas sustantivas $(26,5 \%)$ -n especial objetivas $(14,4 \%)$, índices muy superiores a los representativos de los demás escritores; sólo Quevedo está cerca de Cervantes, tanto en lo que respecta a la subordinación sustantiva en general $(24,1 \%)$, cuanto en lo que se refiere a la sustantivación objetiva $(16,4 \%)^{19}$. Esta elevada proporción de oraciones sustantivas podría tal vez llevar a pensar que ambos escritores privilegian ese tipo de relación oracional primario, esencial, en detrimento de otras relaciones secundarias, complementarias, como es la hipotaxis adjetiva, puntualizadora, la cual es aún más reducida en Quevedo $(11,9 \%)$ que en Cervantes $(14,4 \%)$, y en ambos muy alejada de los índices alcanzados por Nebrija $(28,8 \%)$ o por Hernán Cortés $(23,6 \%)$. Pero ello sería hipótesis que requeriría de un análisis mucho más detenido y pormenorizado de lo que aquí pretendo hacer.

18 A la acusada diferencia existente entre las estructuras sintácticas de la prosa cervantina y los de los escritores mexicanos de nuestro siglo me referiré más adelante.

19 Cf., a este respecto, «Una nota sobre el estilo de Quevedo», incluido en el libro citado en la n. 4, p. 172. 
De cualquier modo, no deja de ser digna de consideración la coincidencia que, en este pormenor, se da entre Cervantes y Quevedo.

Llama también la atención el alto índice proporcional de las relaciones hipotácticas $(73,3)$ de la prosa cervantina, sólo superado por el propio de Nebrija $(80,9 \%)$ y muy ligeramente por Cortés $(74 \%)$. Me atrevo a ver en ello un conocimiento amplio, un dominio firme, con empleo seguro de la compleja trama estructural de la sintaxis española, frente a las más sencillas y frecuentadas - usuales- construcciones paratácticas ${ }^{20}$.

Merece una consideración particular, por último, la enorme distancia que se observa entre la sintaxis cervantina y la que representa, en promedio, a los escritores mexicanos contemporáneos. Las construcciones paratácticas utilizadas por éstos (50,4\%) duplican casi a las empleadas por Cervantes $(26,8)$, en tanto que las más complejas estructuras hipotácticas de la prosa cervantina $(73,3 \%)$ superan en casi el $50 \%$ a los empleados por los escritores mexicanos $(49,6 \%)$. Inclinaría ello a pensar que tan notable diferencia podría deberse a la distancia temporal, a la evolución histórica de la lengua en su plano sintáctico. Pero sería conclusión engañosa.

En efecto, esos porcentajes que proporciono de la sintaxis de la cláusula contemporánea representan un promedio general en que van incluidos autores de muy distintos géneros y muy diversos estilos, entre ellos Juan Rulfo, cuya esquemática sencillez sintáctica se iguala con la de la expresión popular coloquial, alejándose de los patrones expresivos de los otros escritores ${ }^{21}$. Pero si atendemos a las estructuras sintácticas -el manejo de la lengua- de otros escritores mexicanos más cultos o «literarios", como Alfonso Reyes, veremos cómo esa posible causalidad cronológica -esa diferencia de estilos debida a la diferencia de épocas- se borra casi por completo. Veámoslo rápidamente.

La proporción de oraciones regentes en Cervantes $(16,5 \%)$ es casi la misma que en Alfonso Reyes (16,2\%). No se aleja tampoco mucho Reyes de Cervantes en el uso de períodos coordinados: 13.5 por 100 en aquél y 10.3 por 100 en éste, de manera que la suma de estas dos estructuras sintácticas es muy similar en ambos: 29,7 por 100 en la prosa de Reyes y 26,8 por 100 en la de Cervantes, frente, por ejemplo, a la del promedio general de los escritores mexicanos $(50,4 \%)$. En contraparte lógica, la hipotaxis alcanza en ambos escritores índices muy próximos: 73,3 por 100 en el clásico español y 70,3 por 100 en el mexicano. Inclusive el elevado núme-

20 Que, naturalmente, son muy escasas en Nebrija $(7,2 \%)$ y, aunque no tan extremadamente, en Cervantes $(10,3 \%)$.

21 Cf. los datos estadísticos reunidos en las pp. 101-102 del libro citado en la nota 4. 
ro proporcional de subordinadas sustantivas que parecía caracterizar la prosa cervantina $(26,5 \%)$ halla su parangón en la alfonsina, que se aproxima a aquél extraordinariamente $(24,3 \%)$. No se trata, pues - 0 , al menos, no se trata solamente- de diferencias de época, sino de diferencias de estilo personal. Creo que también la honda formación literaria clásica de Alfonso Reyes desempeña algún papel importante en todo ello. Que el factor "género literario" -el ensayo, en el caso de los textos de Reyes por mí analizados- tampoco parece haber sido el determinante de esa proximidad sintáctica. En efecto, otro de los escritores mexicanos por mí considerados, Octavio Paz, lo fue en cuanto ensayista ${ }^{22} \mathrm{y}$, sin embargo, su prosa no alcanzaba la riqueza y complejidad de la cervantina ni de la alfonsina. Compárense los índices proporcionales de las diversas construcciones sintácticas empleadas por $\mathrm{Paz}$ con las correspondientes de Cervantes y Reyes recogidas líneas antes: Oraciones regentes $=21,9 \%$; períodos coordinados $=24,4 \%$; total de construcciones paratácticas $=46,3 \%$; hipotaxis $=53,7 \%$.

La prosa de Cervantes, en síntesis y en conclusión, parece caracterizarse, desde el punto de vista gramatical, por su gran variedad, por su riqueza y por su complejidad sintáctica.

JUAN M. LOPE BLANCH

Universidad Nacional Autónoma

El Colegio de México

${ }^{22}$ Mi análisis se basó en pasajes de El laberinto de la soledad, obra acaso un tanto juvenil. Sería interesante hacer ahora una cala en la prosa del Octavio Paz maduro. Imposible adivinar qué resultados se obtendrían, pues la edad no es el único condicionante del estilo personal. 